\title{
ПРЕОДОЛЕНИЕ ГЕОГРАФИЧЕСКИХ БАРЬЕРОВ В ЛЕЧЕНИИ ОСТРОГО ИНФАРКТА МИОКАРДА В РОССИИ
}

\author{
СЕРГЕЙ ТИМОНИН, АННА КОНЦЕВАЯ, МАРТИН МАККИ, ДЭВИД ЛЕОН
}

\begin{abstract}
За прошедщее десятилетие в России существенно увеличилось число медицинских организаций, выполняющих высокотехнологичные малоинвазивные операчии при остром коронарном синдроме чрескожные коронарные вмешательства (ЧКВ). В данной работе мы оцениваем степень влияния географических барьеров на доступность населения к этому наиболее эффективному способу лечения острого коронарного синдрома, в том числе инфаркта миокарда.
\end{abstract}

Нами была собрана информаџия о медиџинских организаџиях, выполнявших ЧКВ в 2010 и 2015 г2., а также данные о численности населения муниципальных районов и городских округов в России. Методами сетевого анализа было оченено время транспортировки и расстояние от физического центра каждого муниципального района/городского округа до ближайшего ЧКВ- центра в России. Расчеты были выполнень с использованием графа улично-дорожной сети

В период с 2010 по 2015 г. число ЧКВ-центров в России увеличилось со 144 до 260. Медианное время доезда до ближайшего ЧКВ-цеентра составило 48 минут в 2015 г. (в 2010 г. - 73 минуты). Две трети городского населения в 2015 г. могли быть доставлены в ближайший ЧКВ-центр за 60 минут и быстрее, а среди сельского населения такую возможность имела только одна пятая часть потенциильных пациентов. Создание 67 новых ЧКВ-центров в тех городских округах, где в настоящий момент имеется их дефищит, увеличит долю населения, находящегося в 60-минутной зоне доезда до ЧКВ- иентра, до 62\%, что эквивалентно 5,7 млн человек, для которых на данный момент невозможен своевременный доступ к данному виду вмешательства.

В период между 2010 и 2015 г. происходило значительное, но неравномерные сокращение времени доезда до ЧКВ-центров. Несмотря на позитивнье тенденции, Россия еще не приблизилась к уровню доступа, наблюдающегося в сопоставимых странах с большой территорией и неравномерно размещенным населением, таких как Австралия и Канада. Открытие относительно небольшого числа новых ЧКВ-центров (отделений) могло бы существенно улучшить доступ к медицинской помощи, тем самым сократив имеющееся неравенство.

Ключевые слова: первичное чрескожное коронарное вмешательство (ЧКВ), инфаркт миокарда (ИМ), транспортная доступность, время доезда, Россия.

СЕРГЕЙ АНДРЕЕВИч ТИМОНИН (stimonin@hse.ru), НАЦИОНАЛЬНЫЙ ИССЛЕДОВАТЕЛЬСКИЙ УНИВЕРСИТЕТ «ВЫСШАЯ ШКОЛА ЭКОНОМИКИ», РОссия.

АННА ВАСИЛЬЕВНА КОНЦЕВАЯ, НАЦИОНАЛЬНЫЙ МЕДИЦИНСКИЙ ИССЛЕДОВАТЕЛЬСКИЙ ЦЕНТР ПРОФИЛАКТИЧЕСКОЙ МЕДИЦИНЫ МИНИСТЕРСТВА ЗДРАВООХРАНЕНИЯ РФ, РОССИЯ.

ДЭВИД ЛЕОН, ЛОНДОНСКАЯ ШКОЛА ГИГИЕНЫ И ТРОПИЧЕСКОЙ МЕДИЦИНЫ, ВЕЛИКОБРИТАНИЯ.

МАРТИН МАККИ, ЛОНДОНСКАЯ ШКОЛА ГИГИЕНЫ И ТРОПИЧЕСКОЙ МЕДИЦИНЫ, ВЕЛИКОБРИТАНИЯ.

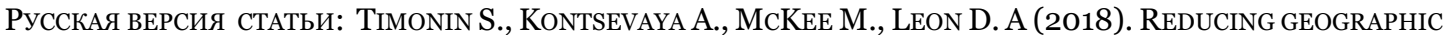
INEQUALITIES IN ACCESS TIMES FOR ACUTE TREATMENT OF MYOCARDIAL INFARCTION IN A LARGE COUNTRY: THE EXAMPLE OF RUSSIA // INTERNATIONAL JOURNAL OF EPIDEMIOLOGY. 47(5): 1594-1602. DOI.ORG/10.1093/IJE/DYY146

АВТОРЫ ВЫРАЖАЮТ БЛАГОДАРНОСТЬ АЛЕКСЕЮ ЩУРУ И ВЕРЕ КУСАКИНОЙ ЗА ПОМОЩЬ В ПОДГОТОВКЕ РУССКОЙ ВЕРСИИ СТАТЬИ.

ИССЛЕДОВАНИЕ ФИНАНСИРОВАЛОСЬ В РАМКАХ ПРОГРАММЫ ГОСУДАРСТВЕННОЙ ПОДДЕРЖКИ ВЕДУЩИХ УНИВЕРСИТЕТОВ РОССИЙСКОЙ ФЕДЕРАЦИИ «5-100» И МЕЖДУНАРОДНОГО ПРОЕКТА ПО СЕРДЕЧНО-СОСУДИСТЫМ ЗАБОЛЕВАНИЯМ В РОССИИ, ПОДДЕРЖАННОГО ФОНДОМ WELLCOME TRUST (100217).

СТАТЬЯ ПОСТУПИЛА В РЕДАКЦИЮ В НОЯБРЕ 2018 Г. 


\section{Ключевые сообщения:}

- $\quad$ в то время как появление малоинвазивных технологий изменило стратегию лечения пациентов с острым инфарктом миокарда (ОИМ), страны с большой территорией, такие как Россия, сталкиваются со сложностями в обеспечении равного доступа к подобного рода технологиям.

- Число больнии, в которых выполняется чрескожное коронарное вмешательство (ЧКВ) в России, почти удвоилось в период между 2010 и 2015 г. (со 144 до 260 медицинских организаций), что демонстрирует существенный прогресс в предоставлении современной медицинской помощи пациентам с ОИМ.

- $\quad$ В 2015 г. около половины взрослого населения России старше 40 лет проживало на расстоянии одного часа доезда до ближайшего ЧКВ-центра; при этом имело место выраженное географическое неравенство, в особенности между городским и сельским населением. Создание 67 новых ЧКВ-центров (отделений в стационарах) в крупных городских округах, в которых на данный момент отсутствует возможность оказания данного вида медицинской помощи, способно улучшить общую доступность, позволив России приблизиться к Австралии и Канаде по доле людей, живущиих в 60-минутной зоне доступности.

- Для регионов с малочисленными, редко расположенными населенными пунктами, возможно, лучшим решением будет оказание медицинской помощи в санитарном транспорте или в медицинских организациях, не выполняющих ЧКВ, с последующей транспортировкой в ЧКВ-центры наземным или воздушным транспортом (по показаниям).

\section{ВВЕДЕНИЕ}

В последние десятилетия оказание медицинской помощи при острых и неотложных состояниях (таких как травма, инсульт, острый коронарный синдром) претерпело кардинальные изменения в результате технологических, фармакологических и организационных улучшений. Всех пациентов, оказавшихся в таких состояниях, объединяет необходимость незамедлительной транспортировки в медицинские центры, оснащенные соответствующим оборудованием и имеющие высококвалифицированный персонал [Ramsay et al. 2015; Dégano et al. 2015]. Первичное чрескожное коронарное вмешательство (ЧКВ) - наиболее предпочтительная стратегия реперфузии (восстановления кровотока в инфаркт-связанной артерии) для пациентов, перенесших острый инфаркт миокарда [Keeley, Boura, Grines 2003]. Вместе с тем для достижения наилучшего терапевтического эффекта лечение должно быть инициировано в максимально сжатые сроки [Nallamothu et al. 2015; Pinto et al. 2006]. Согласно современным американским и европейским рекомендациям, восстановление кровотока должно произойти не позднее, чем через 90-120 минут после появления симптомов [Steg et al. 2012; Anderson et al. 2013]. Однако есть множество факторов, которые могут возникнуть на пути пациента от момента возникновения симптомов до начала выполнения соответствующего вмешательства в стенах медицинской организации. Часть временных задержек вызвана тем обстоятельством, что пациент своевременно не распознает потенциальную опасность 
симптомов и не решается обратиться за медицинской помощью. Кроме того, есть задержки, связанные с транспортировкой пациента до ЧКВ-центра; причем расстояние является особенно серьезной проблемой в тех странах, где население распределено неравномерно на больших территориях, таких как США, Канада, Австралия и Россия. Наконец, задержки могут возникнуть на госпитальном этапе.

Таким образом, формирование национальной «инфарктной сети» должно происходить с учетом географических особенностей расселения населения. В исследованиях, проведенных в США [Nallamothu et al. 2006], Австралии [Coffee et al. 2012] и Канаде [Patel et al. 2010], оценены доли взрослого населения, которое, в случае необходимости, теоретически может быть доставлено в ближайший ЧКВ-центр в течение определенного периода времени. В США почти 80\% взрослого населения в 2000 г. проживало в часовой зоне доступности от ближайшего ЧКВ-центра. В 2006 г. в Австралии примерно 68\% людей старше 55 лет жило в часовой доступности от отделений неотложной кардиологии. Однако эти люди были сосредоточены только в 18\% административных районов, что отражает крайне неравномерное распределение населения в Австралии. Исследование, проведенное в Канаде, показало, что около 64\% людей в возрасте 40 лет и старше имели своевременный доступ к ЧКВ-центрам. При этом в каждой стране в уровне доступа к ЧКВ-центрам наблюдались огромные региональные различия.

Признавая очень высокий, хотя и снижающийся с середины 2000-х годов [Roth et al. 2017; Grigoriev et al. 2014], уровень смертности от болезней системы кровообращения в России, российское правительство запустило приоритетный национальный проект «Здоровье» с акцентом на борьбу с сердечно-сосудистыми заболеваниями [Popovich et al. 2011]. Проект включал повышение доступности малоинвазивных эндоваскулярных методов лечения. Его реализация позволила значительно увеличить число проведенных операций: количество ЧКВ при остром коронарном синдроме увеличивалось с 1500 в 2001 г. до более 100 тыс. вмешательств в 2015 г. [Бокерия, Алекян 2011; 2016]. Более подробно последние тенденции в ведении пациентов с инфарктом миокарда в России представлены в Приложении.

До сих пор значительная часть инвестиций на создание эндоваскулярной службы была ориентирована на крупные медицинские организации, имеющие необходимый кадровый и технологический потенциал для развития соответствующего направления. Дальнейшие приоритеты и подкрепляющие их бюджетные ассигнования, как нам кажется, должны быть направлены более таргетно с целью географического расширения сети ЧКВцентров и тем самым увеличения доступности лечения для населения. Пока, насколько нам известно, не было предпринято никаких систематических попыток оценить масштаб и характер географических барьеров на пути к обеспечению равного и своевременного доступа к лечению инфаркта миокарда (ИМ) в России.

В данном исследовании мы оценили расстояния, выраженные во времени доезда до ближайшей больницы, проводящей ЧКВ, чтобы установить долю населения, которое может при идеальных условиях иметь быстрый доступ к ЧКВ-центру, и исследовали влияние расширения сети на покрытие недостаточно обслуживаемых районов. 


\section{ДАННЫЕ И МЕТОДЫ}

\section{Источники данных}

Центры рентгеноэндоваскулярной диагностики и лечения, выполнявшие в 2010 и 2015 г. ЧКВ при остром коронарном синдроме, были идентифицированы с помощью бюллетеней, ежегодно публикуемых Национальным медицинским исследовательским центром сердечно-сосудистой хирургии им. А.Н. Бакулева [Бокерия, Алекян 2011: 2016]. По названию больниц мы определили адреса и географические координаты каждой из них и создали пространственный набор данных для отображения объектов на карте и использования в последующем моделировании в геоинформационной среде.

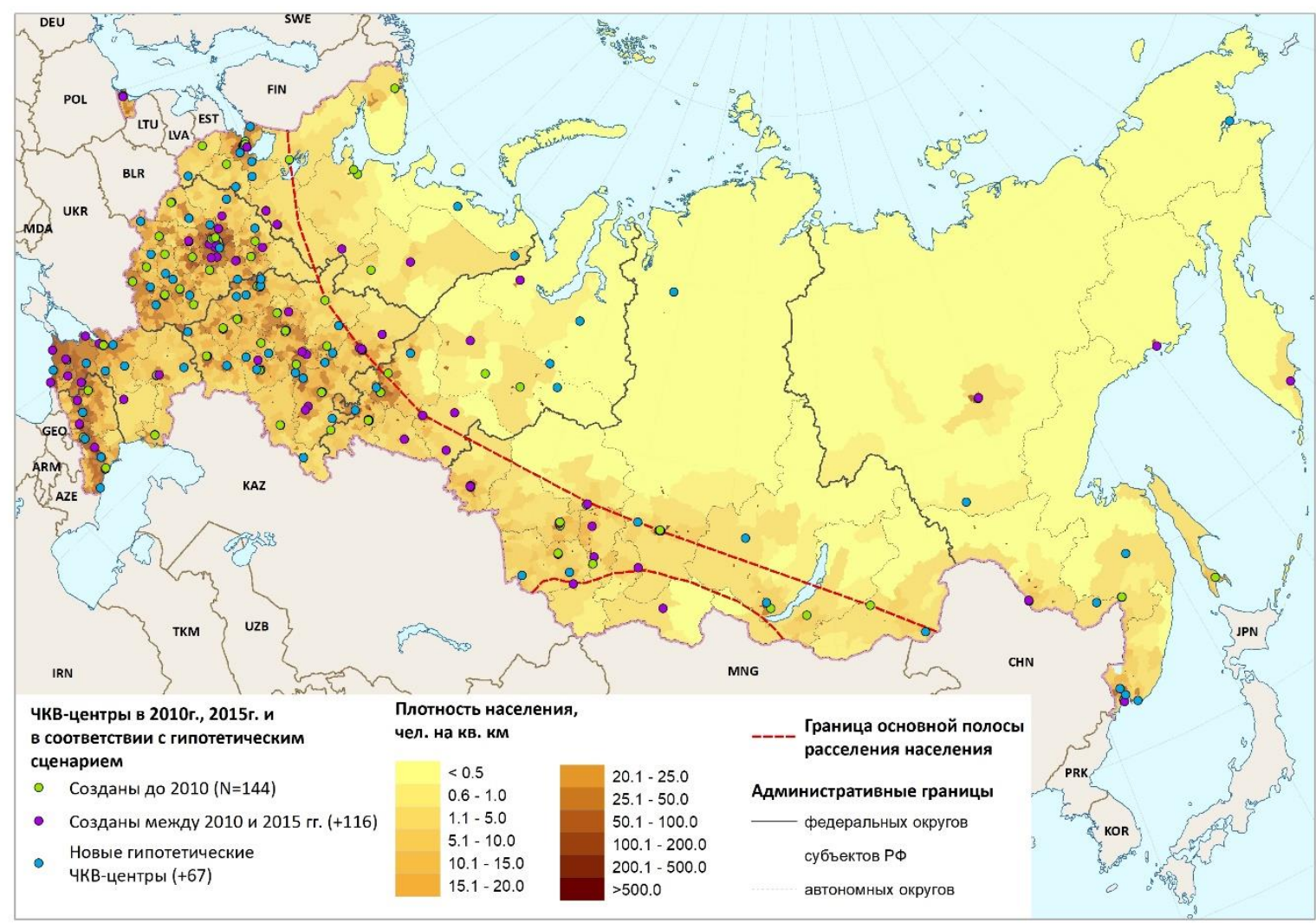

Рисунок 1. Расположение ЧКВ-центров в России в 2010 и 2015 гг. и в соответствии со сценарием добавления новых гипотетических центров $(\mathrm{N}=67)$

Оценки численности и структуры населения были получены из Всероссийской переписи населения 2010 г. для 2577 муниципальных районов и городских округов в 83 регионах Российской Федерации. Мы будем использовать термин «муниципалитет» для обозначения всех единиц муниципального деления верхнего уровня. В их число входят 236 внутригородских районов Москвы и Санкт-Петербурга со средней численностью населения 69420 человек; 516 городских округов со средней численностью населения 131560 человек; 1825 муниципальных районов со средней численностью населения 32100 человек. Внутригородские районы и городские округа имеют преимущественно городское население (100 и 97\% соответственно), в то время как муниципальные районы смешанное, в среднем $60 \%$ их населения проживает в сельской местности. Эти три типа районов также значительно отличаются по площади. В среднем городские округа в 10 раз 
больше, чем внутригородские районы, и в 10 раз меньше муниципальных районов. Неравномерное распределение населения по территории страны показано на рисунке 1. Почти 85\% населения проживает в 78\% муниципалитетов, расположенных на 22\% территории России.

В процессе геоинформационного моделирования были использованы три пространственных набора данных. Первый набор данных (полигональный) описывает муниципалитеты $(\mathrm{N}=2577)$, покрывающие территорию всей страны. Второй точечный набор данных отражает локализацию жилых строений в городах с населением более 1 млн человек. Третий интегрированный набор данных содержит улично-дорожную сеть.

Первичный источник для двух первых наборов данных (проект OpenStreetMaps, OSM) - открытый источник географических данных, создаваемый любителями и профессионалами. Данные для муниципалитетов были тщательно выверены на полноту и топологию и скорректированы авторами там, где это было необходимо. Набор точечных данных с домами в крупных городах был использован без изменений.

Граф улично-дорожной сети был предоставлен компанией HERE. Данные компании HERE имеют значимые преимущества над иными провайдерами данных в России: карта дорог топологически корректна и покрывает территорию всей страны, отражает актуальное состояние улично-дорожной сети и представлена в формате, пригодном для использования в целях моделирования. Дорожная сеть состоит из многочисленных сегментов (edges), связанных точками пересечения - узлами (nodes). Для каждого сегмента рассчитана средняя скорость на основе таких факторов, как класс дороги, результаты измерения траффика и оценка скорости полевыми командами. Весь анализ выполнен с использованием программного обеспечения ArcGIS 10.1.

\section{МОДЕЛИРОВАНИЕ ВРЕМЕНИ ДОЕЗДА ДО ЧКВ-ЦЕНТРОВ}

Мы оценивали время доезда от муниципалитетов до ЧКВ-центров путем построения маршрутов от физических центроидов (географических центров каждого муниципалитета) до больниц. Моделирование выполняли по трем сценариям. Первый - для 2010 г. (число ЧКВ-центров $=144)$, второй - для 2015 г. $(\mathrm{n}=260)$. Для третьего сценария $(\mathrm{n}=327)$ мы добавили 67 новых гипотетических ЧКВ-центров в недостаточно обслуживаемые городские округа. Шестьдесят три из этих «новых» ЧКВ-центров были помещены в города с населением 75 тыс. человек и выше, где время, затрачиваемое на дорогу до ближайшего существующего ЧКВ-центра, было более 60 минут. Четыре других гипотетических ЧКВцентра были помещены в региональные столицы, в которых вообще не проводили никаких чрескожных коронарных вмешательств.

Мы внесли несколько уточнений там, где географические особенности могли привести к ошибочной оценке времени доезда. Во-первых, если географический (физический) центр муниципалитета располагался на удалении более чем 25 километров от ближайшего участка дороги, мы использовали местоположение крупнейшего по численности поселения данного муниципалитета в качестве его центра. Во-вторых, в городских округах с населением свыше миллиона человек (кроме Москвы и Санкт- 
Петербурга, разделенных на внутригородские районы) мы произвели дополнительные расчеты для оценки времени доезда от каждого дома в городе до ближайшего ЧКВ-центра. Среднее значение этих вычислений используется в качестве конечного времени доезда для каждого из этих городских округов. Вместе с тем анализ чувствительности показал, что эти корректировки незначительно повлияли на наши основные результаты. В любом случае практически все жители крупнейших городов проживали в часе езды, и, напротив, практически никто в малонаселенных сельских районах не жил на удалении 60-120 минут от ЧКВ-центров.

В реальной жизни в большинстве случаев пациентов доставляют в ЧКВ-центр в том регионе, в котором они проживают, исходя из чисто административного принципа. Это происходит несмотря на тот факт, что ближайший ЧКВ-центр может оказаться в соседнем субъекте РФ. Мы исследовали различия в показателях доступности населения к ЧКВ в зависимости от того, будут ли всех пациентов доставлять в ближайшую медицинскую организацию вне зависимости от административных границ или только в ближайший центр в регионе, в котором они проживают. Наша основная гипотеза состояла в том, что люди в некоторых периферийных муниципалитетах могут быть быстрее транспортированы в ЧКВ-центр в соседнем регионе, нежели в том, в котором они проживают (рисунок 2).

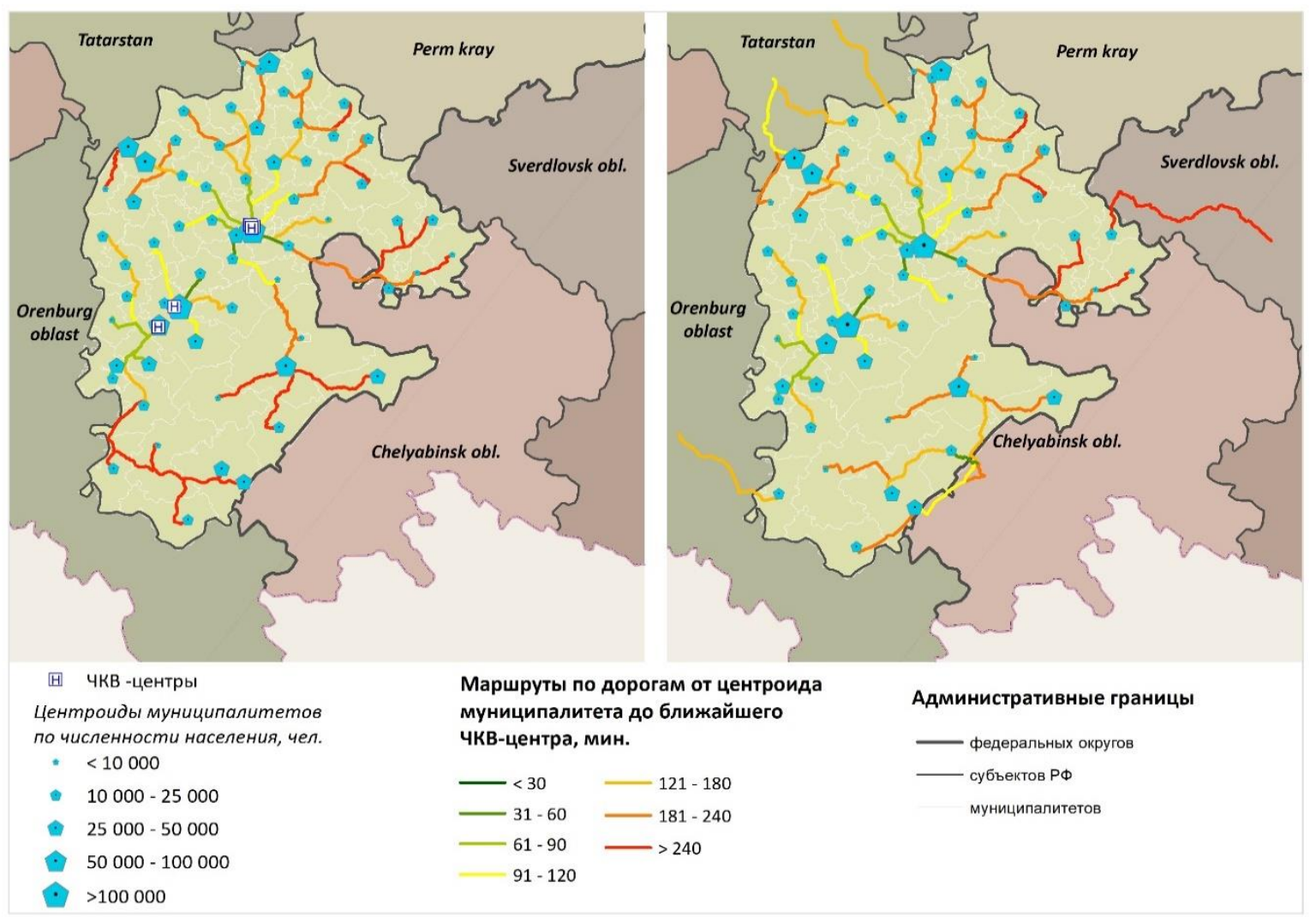

Рисунок 2. Визуализации методики моделирования времени доезда от центра муниципального образования до ближайшего ЧКВ-центра (слева - с учетом административных границ субъектов РФ, справа - без учета) 
Все расчетные показатели оценивались для взрослого населения России в возрасте 40 лет и старше, так как риск перенести острый инфаркт миокарда в более молодых возрастах минимален.

\section{РезУльтаты}

В период с 2010 по 2015 г. количество медицинских организаций, выполняющих ЧКВ при остром коронарном синдроме, почти удвоилось (выросло со 144 до 260). Это увеличение сопровождалось ростом числа проведенных операций (с 12950 до 71180 за тот же период), а также расширением числа регионов, медицинские организации в которых способны выполнять ЧКВ [Бокерия, Алекян 2011; 2016]. На рисунке 1 показано географическое расположение ЧКВ-центров, открытых к 2010 г., появившихся в период с 2010 по 2015 г., 67 новых гипотетических центров. Только один регион на Европейском Севере, два на Дальнем Востоке и один на Северном Кавказе не имели ни одного ЧКВ-центра в 2015 г., тогда как в 2010 г. четверть российских регионов не имели на своей территории ЧКВцентров.

В 2015 г. медианное время доезда до ЧКВ-центра по дороге составляло 48,2 минуты по сравнению с 73,2 минуты в 2010 г. (таблица 1). Около половины всего населения старше 40 лет проживало в часе, а три четверти - в двух часах доезда до ЧКВ-центра. Ожидаемо ЧКВ оказалось более доступным для городских жителей (66\% проживали в часе пути), нежели для жителей сельских районов, где этот показатель составлял только $20 \%$. При использовании двухчасового критерия разница между городскими и сельскими жителями была менее выражена (82\% против 56\%).

Таблица 1. Медианное время доезда и доля населения, проживающего в 60- и 120-минутной зоне доезда до ЧКВ- центра

\begin{tabular}{|c|c|c|c|c|c|c|c|c|c|}
\hline \multirow{2}{*}{\multicolumn{2}{|c|}{$\begin{array}{c}\text { Численность населения } \\
\text { (40+ лет), млн чел. }\end{array}$}} & \multicolumn{4}{|c|}{2010} & \multicolumn{4}{|c|}{2015} \\
\hline & & 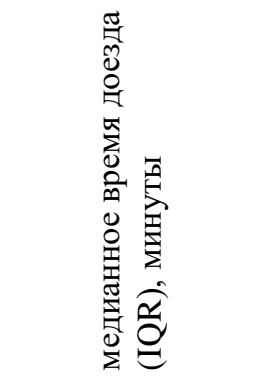 & 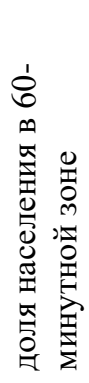 & 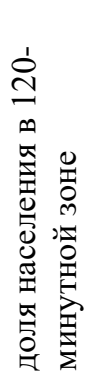 & 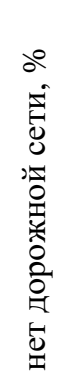 & 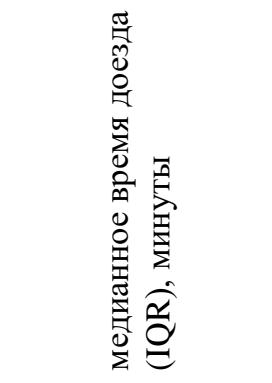 & 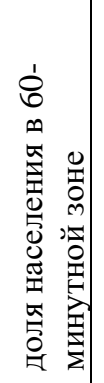 & 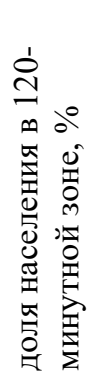 & 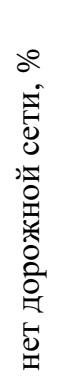 \\
\hline Все население & 67,5 & $73,2(13,5-155,9)$ & 45,1 & 66,0 & 0,6 & $48,2(9,3-118,6)$ & 53,9 & 75,3 & 0,3 \\
\hline Городское & 49,7 & $30,8(10,2-122,6)$ & 56,2 & 74,3 & 0,6 & $15,4(7,3-88,9)$ & 66,0 & 82,3 & 0,3 \\
\hline Сельское & 17,7 & $137,0(84,7-209,7)$ & 14,3 & 42,9 & 0,5 & $109,3(68,8-173,0)$ & 20,3 & 56,2 & 0,3 \\
\hline
\end{tabular}

Примечание: IQR - Межквартильный размах.

На карте (рисунок 3) отображено оцененное время доезда до ближайшего ЧКВцентра для каждого муниципалитета. В то время как многие муниципалитеты в Европейской части России находятся в 60-120-минутной зоне доезда до ЧКВ центров, для значительной части страны время доезда больше 120 минут. На Дальнем Востоке многие центры муниципалитетов находятся на расстоянии более 4 часов езды на автомобиле до 
ближайшего ЧКВ-центра, тогда как арктические и приравненные к ним территории могут вообще не иметь дорожного сообщения с ЧКВ- центром (приблизительно 200 тыс. человек или 0,3\% людей старше 40 лет, проживавших в 40 муниципальных районах в 2015 г.). Наряду с тем, что невысокий уровень доступности к ЧКВ-центрам ожидаем в сельских малонаселенных районах, жители некоторых городских округов и прилегающих к ним районов также испытывают определенный дефицит в доступе к медицинским организациям, выполняющим ЧКВ.

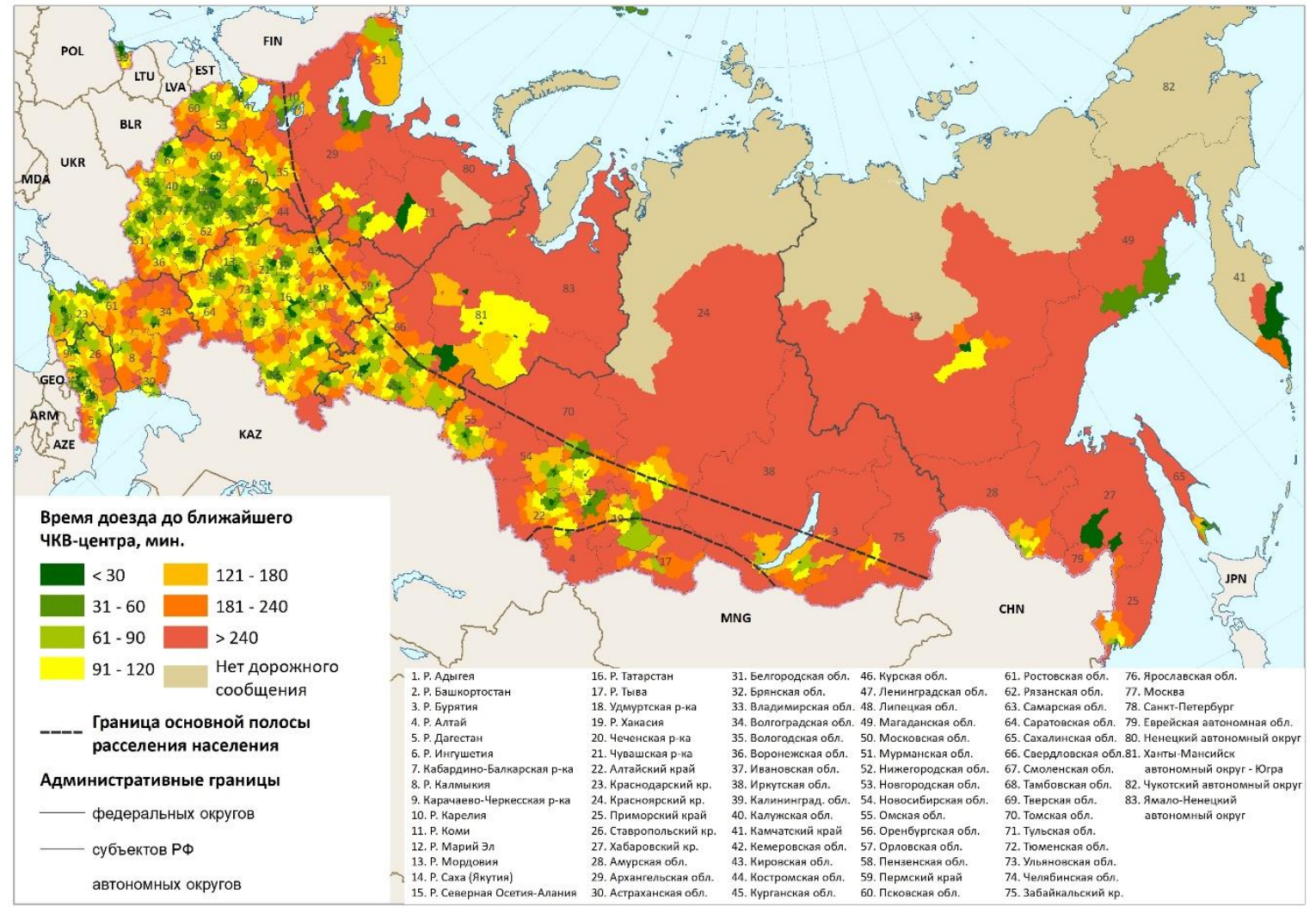

\section{Рисунок 3. Время доезда для ближайшего ЧКВ-центра в России в 2015 г. (по муниципальным районам и городским округам)}

По итогам 2015 г. семь федеральных округов можно было разделить на три группы в соответствии с уровнем доступности ЧКВ: центр и северо-запад Европейской части России (доступность выше, чем в среднем по стране), Поволжье, напоминающее Россию в целом, и другие регионы, где ситуация с доступностью оказалась хуже (таблица П-1 Приложения). Если значительная удаленность муниципалитетов от ЧКВ-центров в Сибири и на Дальнем Востоке может в большей степени объясняться значительными расстояниями и крайне дисперсным характером размещения населения, то это не оправдывает невысокий уровень доступности ЧКВ-центров в густозаселенных регионах юга Европейской части России. Прогресс в обеспечении своевременного доступа к ЧКВ-центрам, имевший место в период между 2010 и 2015 г., наблюдался во всех федеральных округах, но наиболее медленные изменения происходили в регионах Урала. На карте (рисунок 4) показана доля населения старше 40 лет, проживающего в часе езды до ближайшего ЧКВ-центра. 


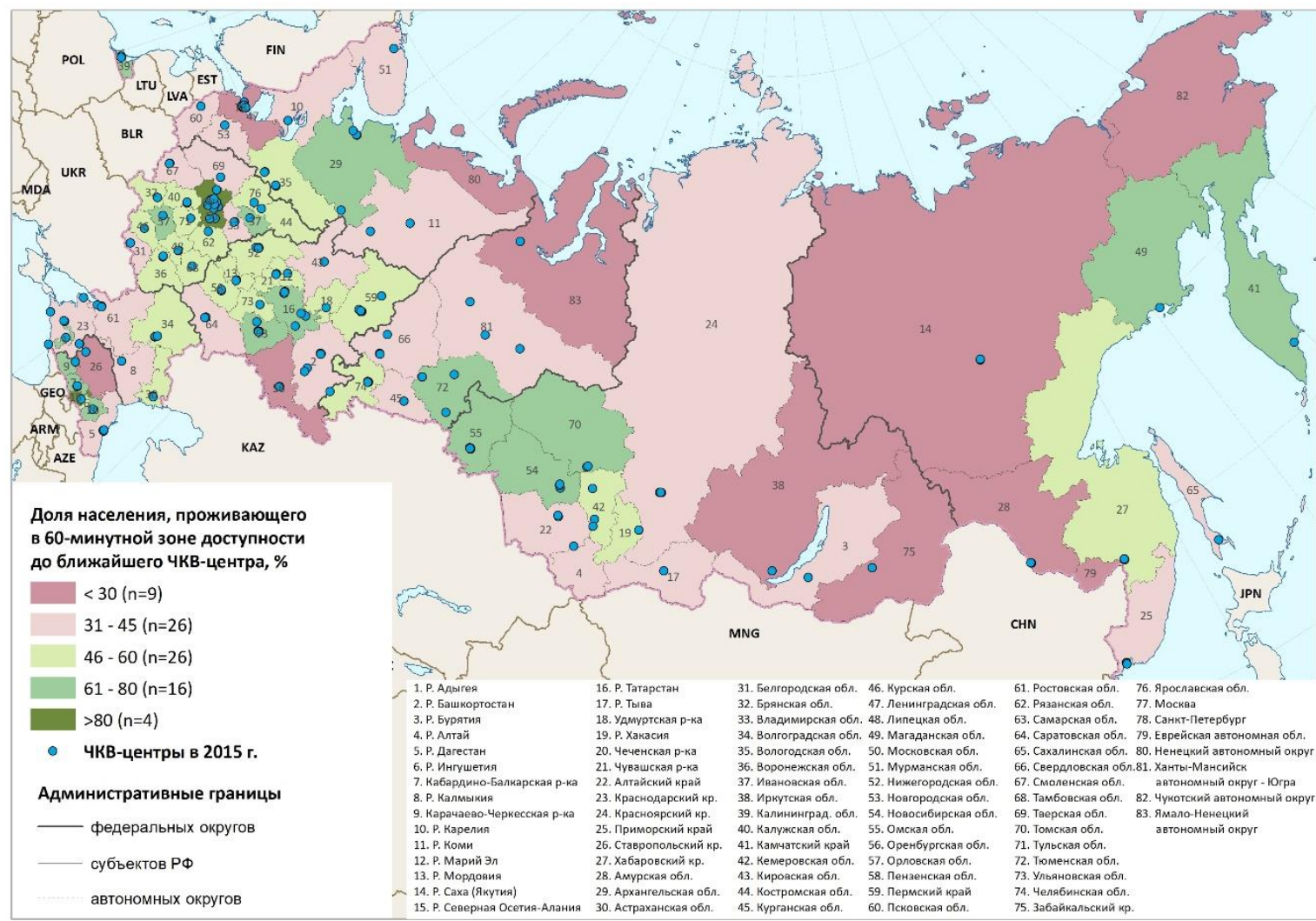

\section{Рисунок 4. Доля населения, проживающая в 60-минутной зоне доступности до ближайшего ЧКВ-центра в 2015 г.}

Представленные выше расчеты отталкиваются от оценки времени доезда до ближайшего ЧКВ-центра вне зависимости от региона его расположения (игнорируя административные границы субъектов РФ). Однако финансирование и предоставление медицинской помощи в большей степени реализуется на территории того региона, в котором проживает пациент или на территории которого он находился в момент возникновения состояния, требующего оказания экстренной медицинской помощи. Для жителей некоторых (чаще всего приграничных) муниципалитетов время доезда до ЧКВ-центра, расположенного в соседнем субъекте РФ, может быть меньше, нежели до ближайшей медицинской организации, расположенной в данном регионе. Для оценки степени влияния административных границ между субъектами РФ на время доезда мы провели анализ чувствительности, позволивший сравнить время, затраченное на доезд до ближайшего ЧКВ-центра с учетом и без учета административных границ. Анализ показал, что в 2015 г. около 7,5 млн человек или 11\% населения старше 40 лет проживали в 400 приграничных муниципалитетах, из которых было бы быстрее добраться до ЧКВцентра, расположенного в соседнем регионе. Еще для 232 тыс. человек, проживающих в 15 муниципалитетах, доступные ЧКВ-центры расположены только в соседних регионах (рисунок 5). Вместе с тем на популяционном уровне устранение эффекта административных границ связано с относительно небольшим увеличением (примерно на 0,5\% или 337,7 тыс. человек) числа тех, кто проживает в 60-минутной зоне доезда, или на 2,3\% (1 456, тыс. человек) тех, кто проживает в 120-минутной зоне доезда. 


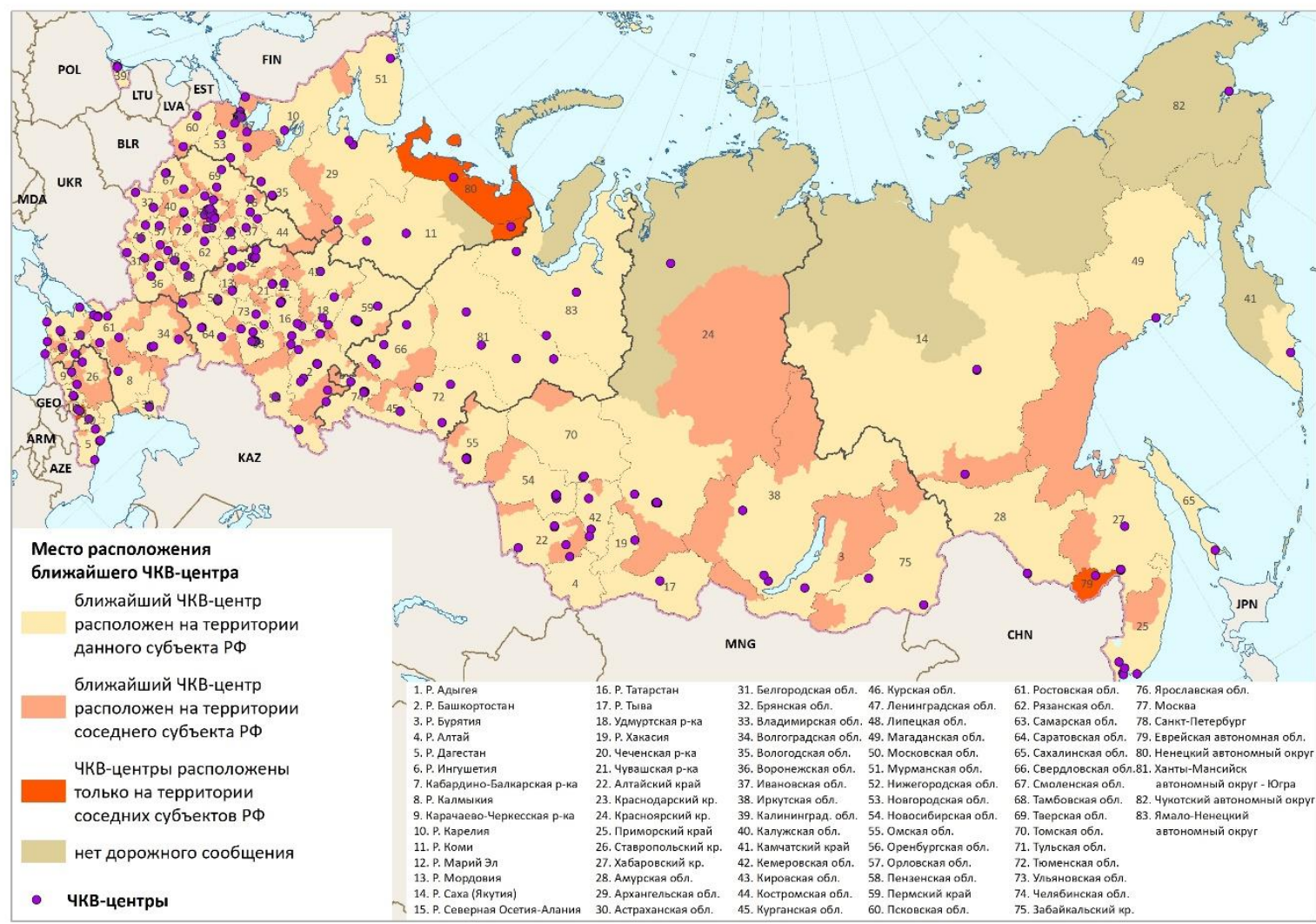

\section{Рисунок 5. Типология муниципалитетов России по близости расположения ЧКВ-центров, 2015}

Таблица 2. Эффект от создания новых 67 ЧКВ-центров в России

\begin{tabular}{|c|c|c|c|c|c|c|c|c|}
\hline \multirow{2}{*}{\multicolumn{2}{|c|}{$\begin{array}{l}\text { Численность (40+ лет), } \\
\text { млн чел. }\end{array}$}} & \multicolumn{3}{|c|}{$\begin{array}{c}\text { Гипотетические условия } \\
\text { (открытие } 67 \text { новых ЧКВ центров) }\end{array}$} & \multicolumn{4}{|c|}{$\begin{array}{l}\text { Изменения в сравнении } \\
\text { с } 2015 \text { г. }\end{array}$} \\
\hline & & 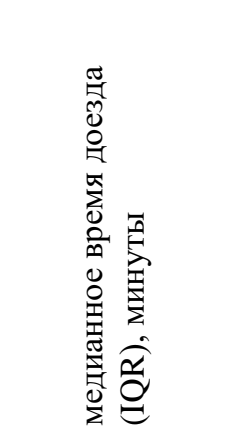 & 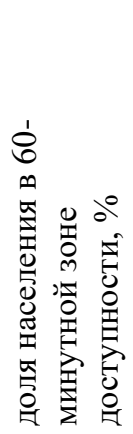 & 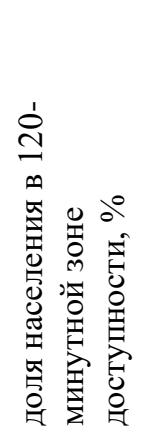 & 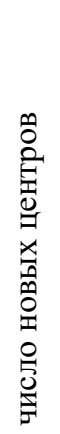 & 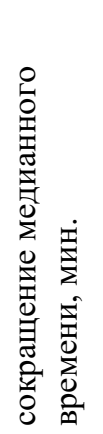 & 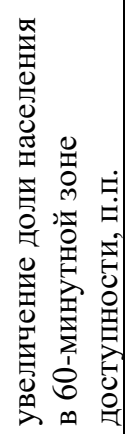 & 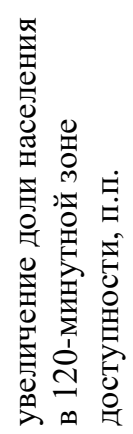 \\
\hline Bce $\mathrm{H}$ & 6 & $34,7(9,0-90,4)$ & 62,1 & 83,6 & 67 & 14,1 & 8,3 & $\overline{8,2}$ \\
\hline Городское & 49,7 & $13,5(7,0-61,9)$ & 74,5 & 89,5 & 67 & 1,9 & 8,5 & 7,2 \\
\hline Сельское & 17,7 & $88,4(56,3-139,5)$ & 28,0 & 67,2 & 0 & 20,9 & 7,7 & 11,0 \\
\hline
\end{tabular}

Примечание: IQR - Межквартильный размах.

Мы также оценили эффект от создания 67 новых ЧКВ-центров (отделений) в городских округах, на данный момент недостаточно обеспеченных этим видом медицинских услуг, или в регионах, вообще не имеющих ЧКВ-центров (рисунок 1). Для России в целом открытие новых центров увеличило бы долю населения, проживающего в 60-минутной зоне доезда до ЧКВ-центра, на 8,3 процентных пункта (8,5 п.п. для городского и 7,7 п.П. для сельского населения) до 62,1\% населения (таблица 2). 
Внутри России положительные эффекты были бы наиболее сильными на юге Европейской части России и Дальнем Востоке (рисунок 6).

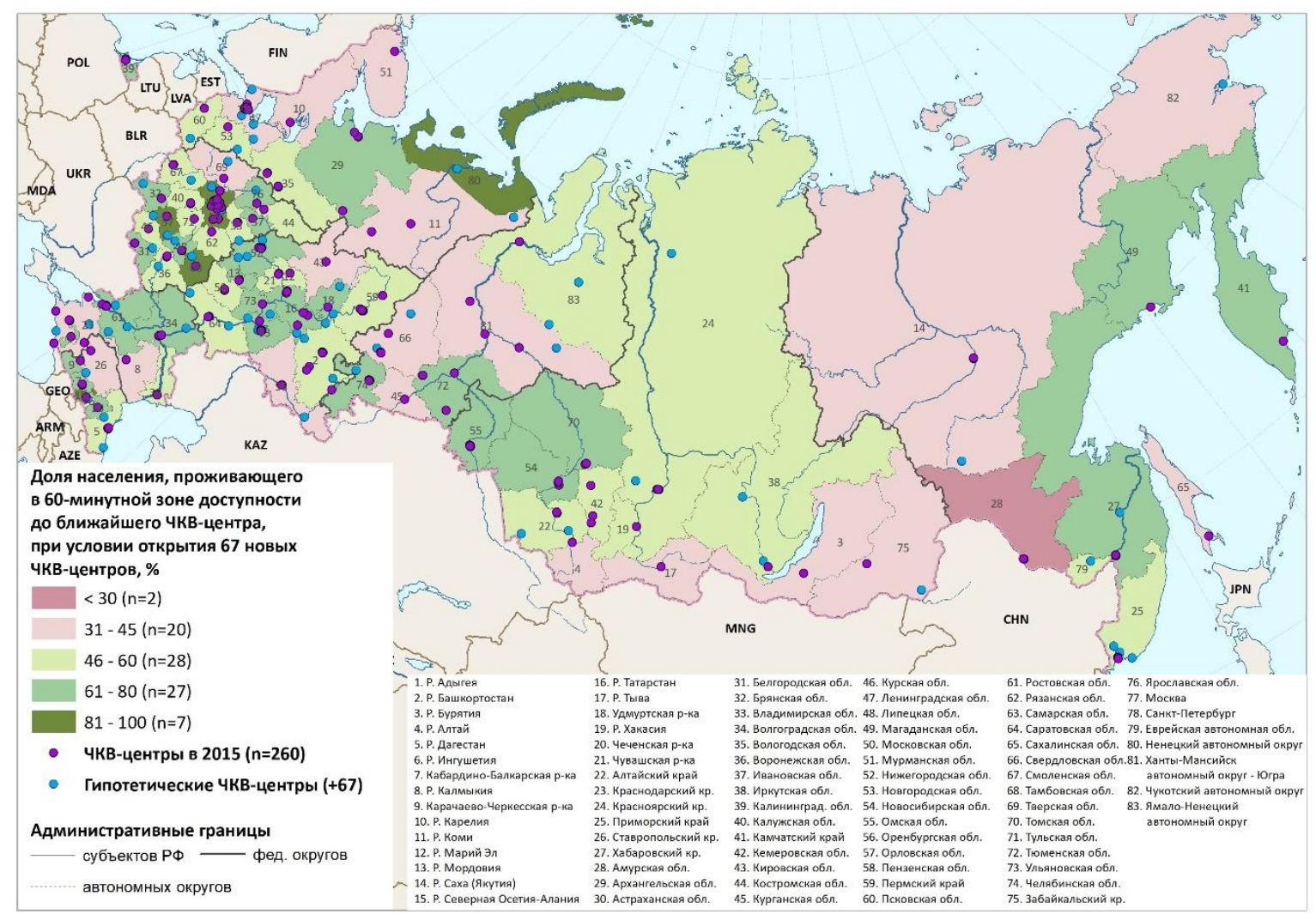

\section{Рисунок 6. Доля населения, проживающего в 60-минутной зоне доступности до ближайшего ЧКВ-центра, при условии открытия 67 новых ЧКВ-центров}

\section{ОБСУЖДЕНИЕ}

Проведенный анализ показал, что существенный рост числа ЧКВ-центров в России в 20102015 гг. привел к заметному повышению уровня доступности черескожных коронарных вмешательств, однако сохраняется существенное географическое неравенство. Даже в 2015 г., по нашим оценкам, почти половина населения проживала более чем в часе езды до ближайшего ЧКВ-центра, четверть - на расстоянии более двух часов.

Некоторая степень неравенства в доступности, безусловно, неизбежна, учитывая площадь территории России и неравномерный характер расселения населения. Однако сегодня оно все еще настолько большое, что вызывает беспокойство. Жители городских округов имеют ощутимо лучший доступ по сравнению с 18 миллионами сельских жителей в возрасте 40 лет и старше, среди которых только один из пяти имел возможность в течение 60 минут добраться до ближайшего ЧКВ-центра. Более того, неравенство между городским и сельским населением даже увеличилось в период между 2010 и 2015 гг. Территории, лучше всего обеспеченные ЧКВ-центрами, располагаются в центре Европейской части России, тогда как Дальний Восток имеет самый низкий уровень обеспеченности: менее 40\% 
его жителей проживают в зоне 60-минутной доступности до ЧКВ-центров (таблица П-1 Приложения).

В то время как экономическая целесообразность создания новых ЧКВ-центров на территориях дисперсного расселения населения требует дальнейшего изучения, необходимость расширения сети ЧКВ-центров в городских округах Юга России и Урала не должна вызывать сомнений (таблица П-2 Приложения). По нашим оценкам, открытие новых 67 ЧКВ-центров (отделений) в густонаселенных, но плохо обслуживаемых городских округах, будет иметь тот же эффект, с точки зрения увеличения доли населения, проживающего в 60-минутной зоне доступности (+8,3 п.п.), что был достигнут при масштабном расширении инфарктной сети, имевшем место в 2010-2015 гг. (+8,8 п.п.). Это доказывает, prima facie, что Россия еще не достигла точки в увеличении ассигнований, когда потенциальные выгоды будут показывать убывающую отдачу.

Как отмечалось выше, в силу административных и финансовых ограничений в настоящее время невозможно в плановом порядке транспортировать пациентов, проживающих в одном регионе, в ЧКВ-центр, расположенный в соседнем субъекте РФ. Вместе с тем наш анализ показывает, что, если бы все пациенты в остром состоянии направлялись в ближайший ЧКВ-центр вне зависимости от того, располагается ли он в регионе проживания пациента или в соседнем, общий эффект был бы более заметным, хотя и не столь существенным на популяционном уровне, как это ожидалось изначально.

Проведенное исследование имеет ряд ограничений. Мы оценивали время в пути только по дорогам, предполагая хорошие условия, которые едва ли достижимы в ночное время и зимние месяцы. Хотя это и выходит за рамки исследования, но качество дорожного покрытия также стоит принимать во внимание. Так, данные по другим странам свидетельствуют о том, что улучшение транспортной инфраструктуры может значимо повысить доступность населения к необходимым видам помощи [Balabanova et al. 2013]. В некоторых случаях для транспортировки пациентов может быть задействована санитарная авиация, хотя, как отмечается в норвежском обзоре, это тоже не является панацеей, учитывая погодные условия [Norum 2010]. Между тем российское правительство инициировало новый приоритетный проект в области здравоохранения «Развитие санитарной авиации» [Паспорт приоритетного проекта...2016], цель которого - увеличение доли лиц, госпитализированных по экстренным показаниям в течение первых суток, проживающих в труднодоступных районах страны ${ }^{1}$. Он предусматривает расходы из федерального бюджета в размере 9,9 млрд рублей в 2017-2020 гг., которые будут направлены в 34 субъекта РФ. Однако маловероятно, что развитие санитарной авиации способно оказать существенное влияние на повышение доступности к ЧКВ-центрам для населения страны в целом.

Во-вторых, наши оценки исходят из упрощенного допущения, что географическое расстояние до ближайшего ЧКВ-центра - единственное ограничивающее условие. Вместе с тем известно, хотя точные данные недоступны, что ЧКВ-центры различаются своей

\footnotetext{
${ }^{1}$ Согласно критериям Минтранса России, 34 субъекта Российской Федерации отнесены к труднодоступным территориям.
} 
мощностью (числом врачей, рентген-операционных и т.д.) и не все из них работают в круглосуточном режиме. Более того, используемые нами параметры в 60 и 120 минут не учитывают реальную ситуацию, когда зачастую между появлением первых симптомов инфаркта миокарда и обращением за медицинской помощью/отправкой в больницу может быть существенный временной лаг. Эти задержки могут быть обусловлены как неумением пациента и его окружения вовремя распознать симптомы острого коронарного синдрома и обратиться за медицинской помощью, так и скоростью реагирования служб скорой медицинской помощи. Исследование, проведенное на данных федерального регистра острого коронарного синдрома (2009-2011 гг., 40 регионов России) показывает, что средний интервал между появлением первых симптомов и вызовом бригады скорой медицинской помощи составлял 158 минут в 2009 г. и 134 минуты в 2011 г. [Ощепкова и др. 2012], в то время как среднее время доставки пациента скорой помощью в больницу составляло 55 минут. По наиболее свежим данным регистра острого коронарного синдрома RECORD3 (охватывает первые шесть месяцев 2015 г., 47 ЧКВ-центров и 2370 пациентов) среднее время от наступления симптомов до вызова скорой помощи составило 3,4 часа - не лучше, чем в 2009-2011 гг. [Эрлих, Грацианский 2016].

В соответствии с нормативно-правовой базой, бригады скорой медицинской помощи (СМП) предоставляют медицинскую помощь всем лицам, находящимся на территории России, в круглосуточном режиме 7 дней в неделю. Расположение и территория обслуживания подстанций СМП определяются численностью и плотностью населения, качеством дорожного покрытия, интенсивностью дорожного трафика и с учетом того, что время доезда до пациентов не должно превышать 20 минут. По данным федерального статистического наблюдения, в 2015 г. в 87,0\% случаев скорая медицинская помощь прибывала в течение 20 минут от момента поступления вызова, однако имели место значительные региональные различия, причиной которых может быть как реальная ситуация, так и искажения в сборе и публикации статистических данных. Тем не менее эти данные недоступны на достаточно дробном уровне, чтобы быть включенными в наш анализ.

В идеале мы бы хотели оценить, как улучшение во времени доступности к медицинской помощи связано со снижением смертности. Стандартизованный коэффициент смертности от инфаркта миокарда для обоих полов сократился с 39,7 до 34,4 на 100 тыс. населения с 2010 по 2015 г. Тем не менее существует множество других факторов, которые могли потенциально внести вклад в снижение смертности от инфаркта миокарда. В этой связи более информативным был бы повозрастной анализ смертности на уровне муниципалитетов, однако данные, которые потребовались бы для такого анализа, в России недоступны.

Некоторые из поднятых вопросов исследуются нами в другой части этого же проекта (международный проект по сердечно-сосудистым заболеваниям в России), где мы отслеживаем в течение 1 года от первого медицинского контакта более чем 1100 случаев лечения острого инфаркта миокарда в 13 регионах России. Однако уже наши текущие выводы ясно показывают масштаб проблемы и имеют политическое значение. Во-первых, несмотря на очевидное увеличение числа ЧКВ-центров на протяжении последнего десятилетия, нам представляется, что их нынешнее количество и размещение недостаточно, 
особенно для юга Европейской части России, Поволжья и Урала. Только путем создания новых ЧКВ-центров Россия могла бы приблизиться к показателям Австралии и Канады по доле людей, проживающих в часе езды до ЧКВ-центра. Во-вторых, кажется очевидной необходимость развития межрегионального сотрудничества, хотя это потребует определенных изменений в текущем подходе к финансированию здравоохранения. Это позволило бы пациентам обращаться за медицинской помощью в соседний регион, если именно там находится ближайшая больница.

Наконец, сталкиваясь с ограниченностью ресурсов, лица, принимающие решения, должны будут расставить приоритеты при ассигновании средств на открытие новых ЧКВцентров или иных медицинских организаций (отделений). Используемый нами подход, основанный на оценке доли населения, которое может получить выгоду от расширения сети ЧКВ-центров, может послужить основой для принятия решений. В некоторых случаях, в частности для регионов с небольшими по численности и дисперсно расположенными населенными пунктами, целесообразно внедрение протоколов оказания более специализированной помощи бригадами СМП и в больницах, не выполняющих ЧКВ, с последующей транспортировкой в ЧКВ-центры.

\section{ЛИТЕРАТУРА}

Бокерия Л.А., Алекян Б. Г. (2011). Рентгенэндоваскулярная диагностика и лечение заболеваний сердия и сосудов в Российской Федераџии - 2010 год. Москва: НЦССХ им. АН Бакулева РАMH. 144 с. ISBN 978-5-7982-0285-0

Бокерия Л.А., Алекян Б.Г. (2016). Рентгенэндоваскулярная диагностика и лечение заболеваний сердиа и сосудов в Российской Федераџии - 2015. Москва: НЦССХ им. А. Н. Бакулева РАМН. 220 с. ISBN 978-5-79820-359-8.

Ощепкова Е.В., Дмитриев В.А., Гриднев В.И., Довгалевский П.Я., Карпов Ю.А. (2012). Трехлетний опыт работы регистра больных с острым коронарным синдромом в региональных сосудистых центрах и первичных сосудистых отделениях. Кардиологический вестник, 2, 5-9.

Паспорт приоритетного проекта "Обеспечение своевременности оказания экстренной медицинской помощи гражданам, проживающим в труднодоступных районах Российской Федерации" (2016). Совет при президенте Российской Федерации. URL: http://government.ru/media/files/xLXSd7WMLJ3HV8fmuvwxjLZx0zrJt3Pr.pdf (данные загружены 21.02.2019).

Эрлих А.Д., Грацианский Н.А. (2016). Российский регистр острого коронарного синдрома «РЕКОРД-3». Характеристика пациентов и лечение до выписки из стационара. Кардиология, 4, 16-24.

Anderson J.L., Adams C.D., Antman E.M., Bridges C.R., Califf R.M., Casey D.E. Jr., Chavey W.E., Fesmire F.M., Hochman J.S., Levin T.N., Lincoff A.M., Peterson E.D., Theroux P., Wenger N.K., Wright R.S., Jneid H., Ettinger S.M., Ganiats T.G., Philippides G.J., Jacobs A.K., Halperin J.L., Albert N.M., Creager M.A., DeMets D., Guyton R.A., Kushner F.G., Ohman E.M., Stevenson W., Yancy C.W. (2013). 2012 ACCF/AHA focused update incorporated into the ACCF/AHA 2007 guidelines for the management of patients with unstable angina/non-ST-elevation myocardial infarction: a report of the American College of 
Cardiology Foundation/American Heart Association Task Force on Practice Guidelines. Circulation, 127(23), e663-828. DOI: 10.1016/j.jacc.2013.01.014.

Balabanova D., Mills A., Conteh L., Akkazieva B., Banteyerga H., Dash U., Gilson L., Harmer A., Ibraimova A., Islam Z., Kidanu A., Koehlmoos T.P., Limwattananon S., Muraleedharan V.R., Murzalieva G., Palafox B., Panichkriangkrai W., Patcharanarumol W., Penn-Kekana L., Powell-Jackson T., Tangcharoensathien V., McKee M. (2013). Good health at low cost 25 years on: lessons for the future of health system strengthening. Lancet, 381, 2118-33. DOI: $10.1016 / \mathrm{S} 0140-6736(12) 62000-5$.

Coffee N., Turner D., Clark R.A., Eckert K., Coombe D., Hugo G., Van Gaans D.,Wilkinson D., Stewart S., Tonkin A. (2012). Measuring national accessibility to cardiac services using geographic information systems. Applied Geography, 34, 445-55. DOI:

10.1016/j.apgeog.2012.01.007.

Dégano I.R., Salomaa V., Veronesi G., Ferriéres J., Kirchberger I., Laks T., Havulinna

A.S., Ruidavets J.B., Ferrario M.M., Meisinger C., Elosua R., Marrugat J.; Acute Myocardial Infarction Trends in Europe (AMITIE) Study Investigators (2015). Twenty-five-year trends in myocardial infarction attack and mortality rates, and case-fatality, in six European populations. Heart, 101(17), 1413-21. DOI: 10.1136/heartjnl-2014-307310.

Grigoriev P., Meslé F., Shkolnikov V.M., Andreev E., Fihel A., Pechholdova M., Vallin J. (2014). The recent mortality decline in Russia: Beginning of the cardiovascular revolution? Population and Development review, 40(1), 107-29. DOI: /10.1111/j.1728-4457.2014.00652.

Keeley E.C., Boura J.A., Grines C.L. (2003). Primary angioplasty versus intravenous thrombolytic therapy for acute myocardial infarction: a quantitative review of 23 randomised trials. Lancet, 361(9351), 13-20.

Nallamothu B.K., Bates E.R., Wang Y., Bradley E.H., Krumholz H.M. (2006). Driving times and distances to hospitals with percutaneous coronary intervention in the United States: implications for prehospital triage of patients with ST-elevation myocardial infarction. Circulation, 113(9), 1189-95.

Nallamothu B.K., Normand S.L., Wang Y., Hofer T.P., Brush J.E. Jr., Messenger J.C., Bradley E.H., Rumsfeld J.S., Krumholz H.M. (2015). Relation between door-to-balloon times and mortality after primary percutaneous coronary intervention over time: a retrospective study. Lancet, 385(9973), 1114-22. DOI: 10.1016/S0140-6736(14)61932-2.

Norum J. (2010). Cardiovascular disease (CVD) in the Norwegian Arctic. Air ambulance operations 1999-2009 and future challenges in the region. Int Marit Health, 62(3), 117-22.

Patel A.B., Tu J.V., Waters N.M., Ko D.T., Eisenberg M.J., Huynh T., Rinfret S., Knudtson M.L., Ghali W.A. (2010). Access to primary percutaneous coronary intervention for STsegment elevation myocardial infarction in Canada: a geographic analysis. Open Med, 4(1), e13-21.

Pinto D.S., Kirtane A.J., Nallamothu B.K, Murphy S.A., Cohen D.J., Laham R.J., Cutlip D.E., Bates E.R., Frederick P.D., Miller D.P., Carrozza J.P. Jr, Antman E.M., Cannon C.P., Gibson C.M. (2006). Hospital delays in reperfusion for ST-elevation myocardial infarction: implications when selecting a reperfusion strategy. Circulation, 114(19), 2019-25.

Popovich L., Potapchik E., Shishkin S., Richardson E., Vacroux A., Mathivet B. (2011). Russian Federation. Health system review. Health Syst Transit, 13(7), 1-190, xiii-xiv.

Ramsay A.I., Morris S., Hoffman A., Hunter R.M., Boaden R., McKevitt C., Perry C., Pursani N., Rudd A.G., Turner S.J., Tyrrell P.J., Wolfe C.D., Fulop N.J. (2015). Effects of 
Centralizing Acute Stroke Services on Stroke Care Provision in Two Large Metropolitan Areas in England. Stroke, 46(8), 2244-51. DOI: 10.1161/STROKEAHA.115.009723.

Roth G.A., Johnson C., Abajobir A. et al. (2017). Global, Regional, and National Burden of

Cardiovascular Diseases for 10 Causes, 1990 to 2015. J Am Coll Cardiol, Jul 4, 70(1), 1-25.

DOI: $10.1016 /$ j.jacc.2017.04.052.

Steg P.G., James S.K., Atar D., Badano L.P., Blömstrom-Lundqvist C., Borger M.A., Di Mario C., Dickstein K., Ducrocq G., Fernandez-Aviles F., Gershlick A.H., Giannuzzi P., Halvorsen S., Huber K., Juni P., Kastrati A., Knuuti J., Lenzen M.J., Mahaffey K.W., Valgimigli M., Van 't Hof A., Widimsky P., Zahger D. (2012). ESC Guidelines for the management of acute myocardial infarction in patients presenting with ST-segment elevation. Eur Heart J, 33(20), 2569-619. DOI: 10.1093/eurheartj/ehs215.

\section{ПРИЛОЖЕНИЕ}

\section{Современная практика ведения инфаркта миокарда в Российской Федерации}

Тромболитическая терапия может проводиться почти во всех центральных районных и городских больницах России, так же, как и подготовленными врачами и фельдшерами скорой медицинской помощи. Согласно официальной статистике Минздрава, с 2010 по 2015 г. доля пациентов с острым инфарктом миокарда, получивших тромболизис в стационаре в первые 12 часов с момента госпитализации, значительно не изменилась (выросла с 26,4 до 25,8\%), в то время как доля проведенных ЧКВ выросла значительно (с $8,2 \%$ в 2010 г. до 41,6\% в 2015 г.). Доля пациентов, получивших тромболизис в машине скорой медицинской помощи, также увеличилось с 2,8 до 6,6\% за тот же период. Удивительно, что почти нет разницы между долей городских и сельских жителей с ИМ, которым был проведен тромболизис бригадой скорой медицинской помощи $(6,7$ и $6,2 \%$ соответственно). В 2015 г. тромболизис на догоспитальном этапе был проведен 13632 раза.

Таблица П-1. Некоторые индикаторы временной доступности ЧКВ-центров в федеральных округах, 2010 и 2015 г.

\begin{tabular}{|c|c|c|c|c|c|c|c|c|c|}
\hline \multirow[b]{2}{*}{ 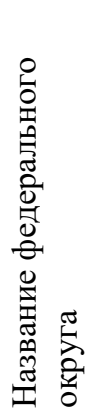 } & \multirow[b]{2}{*}{ 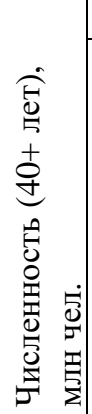 } & \multicolumn{4}{|c|}{2010} & \multicolumn{4}{|c|}{2015} \\
\hline & & 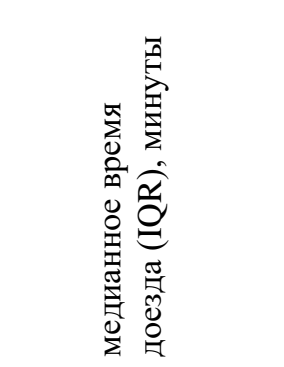 & 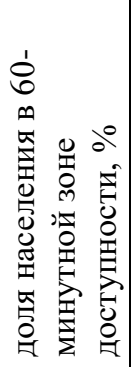 & 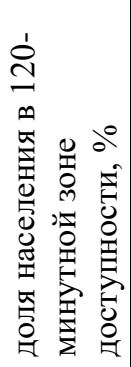 & 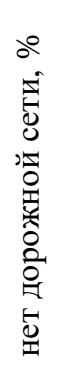 & 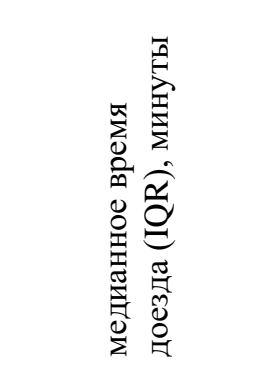 & 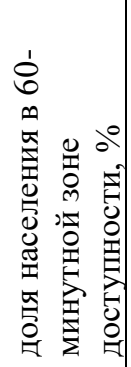 & 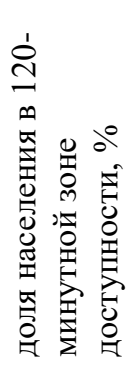 & 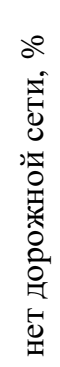 \\
\hline ЦФО & 19,4 & $23,9(9,5-83,3)$ & 64,3 & 86,1 & 0,0 & $14,9(7,2-74,2)$ & 69,1 & 89,6 & 0,0 \\
\hline СЗФО & 6,7 & $23,4(7,2-120,1)$ & 58,1 & 74,9 & 1,2 & $14,8(6,8-104,8)$ & 61,9 & 78,3 & 0,6 \\
\hline ПФО & 14,4 & $80,1(14,1-141,2)$ & 40,9 & 67,3 & 0,0 & $58,3(11,5-124,8)$ & 50,3 & 73,2 & 0,0 \\
\hline ЮФО & 6,7 & $105,2(19,9-173,8)$ & 30,8 & 53,5 & 0,0 & $75,2(8,6-126,7)$ & 43,2 & 72,0 & 0,0 \\
\hline СКФО & 3,5 & $108,7(62,2-165,6)$ & 22,7 & 56,1 & 0,0 & $79,7(31,4-117,2)$ & 41,3 & 76,7 & 0,0 \\
\hline УФО & 5,5 & $100,2(8,8-168,6)$ & 37,8 & 60,5 & 0,6 & $79,4(8,4-134,8)$ & 43,5 & 69,0 & 0,0 \\
\hline СФО & 8,6 & $121,9(19,3-282,8)$ & 35,5 & 49,2 & 1,0 & $71,3(11-221,8)$ & 45,8 & 60,6 & 1,0 \\
\hline ДВФО & 2,8 & $245,9(37,6-657,9)$ & 30,0 & 32,3 & 7,1 & $159,4(34,6-404,8)$ & 38,8 & 42,9 & 2,6 \\
\hline
\end{tabular}

Примечание: IQR - Межквартильный размах. 
Таблица П-2. Эффект от создания новых 67 ЧКВ-центров, по федеральным округам России

\begin{tabular}{|c|c|c|c|c|c|c|c|c|}
\hline \multirow[b]{2}{*}{ 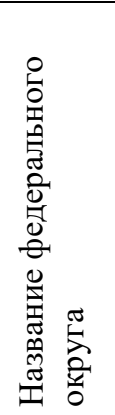 } & \multirow[b]{2}{*}{ 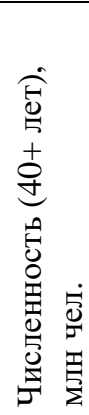 } & \multicolumn{3}{|c|}{$\begin{array}{c}\text { Гипотетические условия } \\
\text { (открытие } 67 \text { новых ЧКВ- центров) }\end{array}$} & \multicolumn{4}{|c|}{ Изменения в сравнении с 2015 г. } \\
\hline & & 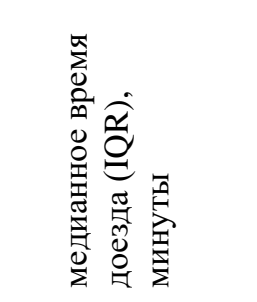 & 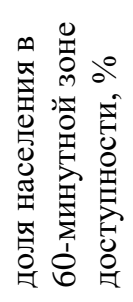 & 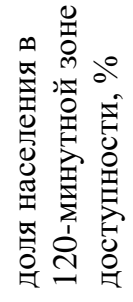 & 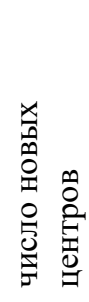 & 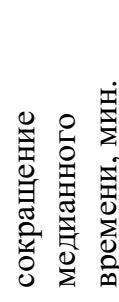 & 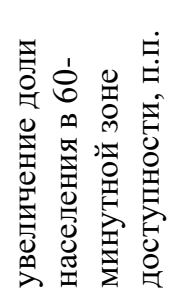 & 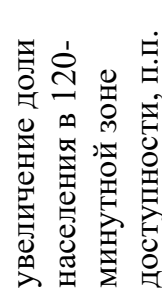 \\
\hline ЦФО & 19,4 & $13,4(7,1-59,8)$ & 75,1 & 94,6 & 13 & 1,5 & 6,0 & 5,0 \\
\hline СЗФО & 6,7 & $13,2(6,7-83,3)$ & 68,0 & 83,3 & 8 & 1,6 & 6,1 & 5,0 \\
\hline ПФО & 14,4 & $35,1(9,9-97)$ & 60,3 & 84,5 & 16 & 23,2 & 10,0 & 11,3 \\
\hline ЮФО & 6,7 & $55,1(8,6-90,4)$ & 52,7 & 84,3 & 6 & 20,2 & 9,5 & 12,2 \\
\hline СКФО & 3,5 & $55,8(13,9-84,9)$ & 56,2 & 85,0 & 4 & 23,9 & 14,9 & 8,3 \\
\hline УФО & 5,5 & $58,9(9,0-116,6)$ & 51,3 & 75,8 & 6 & 20,4 & 7,8 & 6,8 \\
\hline СФО & 8,6 & $47,3(11,1-163,2)$ & 53,5 & 68,3 & 7 & 24,1 & 7,7 & 7,7 \\
\hline ДВФО & 2,8 & $52,6(15,9-235,3)$ & 51,6 & 63,1 & 7 & 106,7 & 12,8 & 20,2 \\
\hline
\end{tabular}

Примечание: IQR - Межквартильный размах. 


\title{
REDUCING GEOGRAPHIC INEQUALITIES IN ACCESS TIMES FOR ACUTE TREATMENT OF MYOCARDIAL INFARCTION IN A LARGE COUNTRY: THE EXAMPLE OF RUSSIA

\author{
SERGEY TIMONIN, ANNA KonTSEVAYA, MARTIN MCKEe, DAVID A LEON
}

\begin{abstract}
Over the past decade, the number of facilities able to perform percutaneous coronary interventions (PCIs) has increased substantially. We quantify the extent to which the constraints of geography make equitable access to this effective technology difficult to achieve.

Hospitals performing PCIs in 2010 and 2015 were identified and combined with data on the population of districts throughout the country. A network analysis tool was used to calculate road-travel times to the nearest PCI facility for those aged 40 years.

The number of PCI facilities increased from 144 to 260 between 2010 and 2015. Overall, the median travel time to the closest PCI facility was 48 minutes in 2015, down from 73 minutes in 2010. Two-thirds of the urban population were within 60minutes' travel time to a PCI facility in 2015, but only one-fifth of the rural population. Creating 67 new PCI facilities in currently underserved urban districts would increase the population share within 60minutes' travel to 62\% of the population, benefiting an additional 5.7 million people currently lacking adequate access.

There have been considerable but uneven improvements in timely access to PCI facilities in Russia between 2010 and 2015. Russia has not achieved the level of access seen in other large countries with dispersed populations, such as Australian and Canada. However, creating a relatively small number of further PCI facilities could improve access substantially, thereby reducing inequality.
\end{abstract}

Key words: percutaneous coronary intervention (PCI), myocardial infarction (MI), travel access, driving times, Russia.

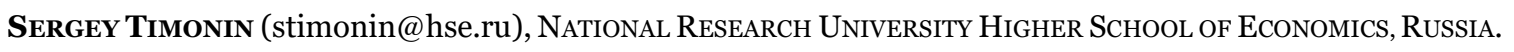

Anna Kontsevaya, National Research Center for Preventive Medicine of the Ministry of Healthcare of THE RUSSIAN FEDERATION, RUSSIA.

Martin McKee, London School of Hygiene and Tropical Medicine, UK.

David A Leon, London School of Hygiene and Tropical Medicine, UK; The Arctic University of Norway, NORWAY.

Russian Version of the Paper: Timonin S., Kontsevaya A., McKee M., Leon D. A (2018). Reducing Geographic INEQUALITIES IN ACCESS TIMES FOR ACUTE TREATMENT OF MYOCARDIAL INFARCTION IN A LARGE COUNTRY: THE EXAMPLE OF RUSSIA // INTERNATIONAL JOURNAL OF EPIDEMIOLOGY. 47(5): 1594-1602. DOI.ORG/10.1093/IJE/DYY146

THIS WORK WAS PARTLY FUNDED THROUGH THE INTERNATIONAL PROJECT ON CARDIOVASCULAR DiSEASE IN RUSSIA SUPPORTED BY A WELCOME TRUST STRATEGIC AWARD (100217) AND WAS SUPPORTED BY THE RUSSIAN ACADEMIC EXCELLENCE PROJECT 5-100.

DATE RECEIVED : NOVEMBER 2018.

\section{REFERENCES}

Anderson J.L., Adams C.D., Antman E.M., Bridges C.R., Califf R.M., Casey D.E. Jr., Chavey W.E., Fesmire F.M., Hochman J.S., Levin T.N., Lincoff A.M., Peterson E.D., Theroux P., Wenger N.K., Wright R.S., Jneid H., Ettinger S.M., Ganiats T.G., Philippides G.J., Jacobs A.K., Halperin J.L., Albert N.M., Creager M.A., DeMets D., Guyton R.A., Kushner F.G., Ohman E.M., Stevenson W., Yancy C.W. (2013). 2012 ACCF/AHA focused update 
incorporated into the ACCF/AHA 2007 guidelines for the management of patients with unstable angina/non-ST-elevation myocardial infarction: a report of the American College of Cardiology Foundation/American Heart Association Task Force on Practice Guidelines. Circulation, 127(23), e663-828. DOI: 10.1016/j.jacc.2013.01.014.

Balabanova D., Mills A., Conteh L., Akkazieva B., Banteyerga H., Dash U., Gilson L., Harmer A., Ibraimova A., Islam Z., Kidanu A., Koehlmoos T.P., Limwattananon S., Muraleedharan V.R., Murzalieva G., Palafox B., Panichkriangkrai W., Patcharanarumol W., Penn-Kekana L., Powell-Jackson T., Tangcharoensathien V., McKee M. (2013). Good health at low cost 25 years on: lessons for the future of health system strengthening. Lancet, 381, 2118-33. DOI: $10.1016 / \mathrm{S} 0140-6736(12) 62000-5$.

Bokeriya L.A., Alekyan B. G. (2011). Rentgenendovaskulyarnaya diagnostika i lecheniye zabolevaniy serdtsa $i$ sosudov v Rossiyskoy Federatsii - 2010 god [Roentgen-endovascular diagnostics and treatment of the heart and blood vessels diseases in the Russian Federation 2010]. Moskva: NCSSKH im. A.N. Bakuleva RAMN [A.N. Bakoulev Scientific Center for Cardiovascular Surgery]. 144 p. ISBN 978-5-7982-0285-0

Bokeriya L.A., Alekyan B. G. (2016). Rentgenendovaskulyarnaya diagnostika i lecheniye zabolevaniy serdtsa $i$ sosudov v Rossiyskoy Federatsii - 2015 [Roentgen-endovascular diagnostics and treatment of the heart and blood vessels diseases in the Russian Federation 2015]. Moskva: NCSSKH im. A.N. Bakuleva RAMN [A.N. Bakoulev Scientific Center for Cardiovascular Surgery]. 220 p. ISBN 978-5-79820-359-8.

Coffee N., Turner D., Clark R.A., Eckert K., Coombe D., Hugo G., Van Gaans D.,Wilkinson D., Stewart S., Tonkin A. (2012). Measuring national accessibility to cardiac services using geographic information systems. Applied Geography, 34, 445-55. DOI: 10.1016/j.apgeog.2012.01.007.

Dégano I.R., Salomaa V., Veronesi G., Ferriéres J., Kirchberger I., Laks T., Havulinna A.S., Ruidavets J.B., Ferrario M.M., Meisinger C., Elosua R., Marrugat J.; Acute Myocardial Infarction Trends in Europe (AMITIE) Study Investigators (2015). Twenty-five-year trends in myocardial infarction attack and mortality rates, and case-fatality, in six European populations. Heart, 101(17), 1413-21. DOI: 10.1136/heartjnl-2014-307310.

Ehrlikh A.D., Gratsiansky N.A. (2016). Rossiyskiy registr ostrogo koronarnogo sindroma «REKORD-3». Kharakteristika patsiyentov i lecheniye do vypiski iz statsionara ['Record-3' Russian Register of acute coronary syndrome: characteristics of patients and treatment before discharge from the hospita]. Kardiologiya [Cardiology], 4, 16-24 (In Russ).

Grigoriev P., Meslé F., Shkolnikov V.M., Andreev E., Fihel A., Pechholdova M., Vallin J. (2014). The recent mortality decline in Russia: Beginning of the cardiovascular revolution? Population and Development review, 40(1), 107-29. DOI: /10.1111/j.1728-4457.2014.00652.

Keeley E.C., Boura J.A., Grines C.L. (2003). Primary angioplasty versus intravenous thrombolytic therapy for acute myocardial infarction: a quantitative review of 23 randomised trials. Lancet, 361(9351), 13-20.

Nallamothu B.K., Bates E.R., Wang Y., Bradley E.H., Krumholz H.M. (2006). Driving times and distances to hospitals with percutaneous coronary intervention in the United States: implications for prehospital triage of patients with ST-elevation myocardial infarction. Circulation, 113(9), 1189-95.

Nallamothu B.K., Normand S.L., Wang Y., Hofer T.P., Brush J.E. Jr., Messenger J.C., Bradley E.H., Rumsfeld J.S., Krumholz H.M. (2015). Relation between door-to-balloon times and 
mortality after primary percutaneous coronary intervention over time: a retrospective study. Lancet, 385(9973), 1114-22. DOI: 10.1016/S0140-6736(14)61932-2.

Norum J. (2010). Cardiovascular disease (CVD) in the Norwegian Arctic. Air ambulance operations 1999-2009 and future challenges in the region. Int Marit Health, 62(3), 117-22.

Oshchepkova E.V., Dmitriev V.A., Gridnev V.I., Dovgalevskij P.Ya., Karpov Yu.A. (2012). Trekhletniy opyt raboty registra bol'nykh s ostrym koronarnym sindromom $\mathrm{v}$ regional'nykh sosudistykh tsentrakh i pervichnykh sosudistykh otdeleniyakh [Three-year experience of register of patients with acute coronary syndrome in the regional vascular centers and primary vascular branches]. Kardiologicheskij vestnik [Heart Gazette], 2, 5-9.

Pasport prioritetnogo proyekta "Obespecheniye svoyevremennosti okazaniya ekstrennoy meditsinskoy pomoshchi grazhdanam, prozhivayushchim $v$ trudnodostupnykh rayonakh Rossiyskoy Federatsii" [Passport of the priority project "Timely support rendering emergency medical access to citizens living in remote and hard to reach areas"] (2016). Sovet pri prezidente Rossijskoj Federacii [Sovet pri prezidente Rossiyskoy Federatsii]. URL: http://government.ru/media/files/xLXSd7WMLJ3HV8fmuvwxjLZx0zrJt3Pr.pdf.

Patel A.B., Tu J.V., Waters N.M., Ko D.T., Eisenberg M.J., Huynh T., Rinfret S., Knudtson M.L., Ghali W.A. (2010). Access to primary percutaneous coronary intervention for STsegment elevation myocardial infarction in Canada: a geographic analysis. Open Med, 4(1), e13-21.

Pinto D.S., Kirtane A.J., Nallamothu B.K, Murphy S.A., Cohen D.J., Laham R.J., Cutlip D.E., Bates E.R., Frederick P.D., Miller D.P., Carrozza J.P. Jr, Antman E.M., Cannon C.P., Gibson C.M. (2006). Hospital delays in reperfusion for ST-elevation myocardial infarction: implications when selecting a reperfusion strategy. Circulation, 114(19), 2019-25.

Popovich L., Potapchik E., Shishkin S., Richardson E., Vacroux A., Mathivet B. (2011). Russian Federation. Health system review. Health Syst Transit, 13(7), 1-190, xiii-xiv.

Ramsay A.I., Morris S., Hoffman A., Hunter R.M., Boaden R., McKevitt C., Perry C., Pursani N., Rudd A.G., Turner S.J., Tyrrell P.J., Wolfe C.D., Fulop N.J. (2015). Effects of Centralizing Acute Stroke Services on Stroke Care Provision in Two Large Metropolitan Areas in England. Stroke, 46(8), 2244-51. DOI: 10.1161/STROKEAHA.115.009723.

Roth G.A., Johnson C., Abajobir A. et al. (2017). Global, Regional, and National Burden of Cardiovascular Diseases for 10 Causes, 1990 to 2015. J Am Coll Cardiol, Jul 4, 70(1), 1-25. DOI: $10.1016 /$ j.jacc.2017.04.052.

Steg P.G., James S.K., Atar D., Badano L.P., Blömstrom-Lundqvist C., Borger M.A., Di Mario C., Dickstein K., Ducrocq G., Fernandez-Aviles F., Gershlick A.H., Giannuzzi P., Halvorsen S., Huber K., Juni P., Kastrati A., Knuuti J., Lenzen M.J., Mahaffey K.W., Valgimigli M., Van 't Hof A., Widimsky P., Zahger D. (2012). ESC Guidelines for the management of acute myocardial infarction in patients presenting with ST-segment elevation. Eur Heart J, 33(20), 2569-619. DOI: 10.1093/eurheartj/ehs215. 